\title{
Os deserdados da indústria: um estudo sobre seus riscos e seus ativos no mercado de trabalho
}

ADALBERTOMOREIRACARDOSO

Professor e pesquisador do IUPERJ

\section{Apresentação}

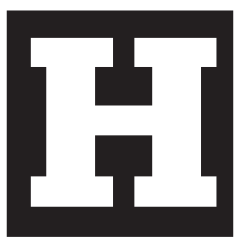

á muito tempo, as ciências sociais brasileiras se dedicam ao tema da reestruturação produtiva e seus impactos sobre as qualificações, o emprego, os salários, as formas de se produzir, as relações de trabalho no nível das empresas, as modalidades de relacionamento horizontal entre trabalhadores e vertical entre estes e seus superiores, as relações de gênero, o papel dos sindicatos nesse processo, dentre outros temas relevantes. Num primeiro momento, dedicada a estudos de caso, nos anos 1990, a literatura passou a privilegiar comparações entre casos e entre setores de produção. Recentemente mais e mais pesquisadores voltam suas energias para o estudo das cadeias produtivas como um todo, ante a constatação de que, em muitos casos, a reestruturação industrial adquire caráter sistêmico. Pode-se dizer que o Brasil consolidou uma literatura abrangente, qualificada, de alto nível teórico e empírico, capaz de dialogar com o que de melhor se produz internacionalmente nesta área.

Entretanto há enorme carência de estudos a respeito dos impactos da reestruturação sobre as opções de trabalho daquelas pessoas que são direta e negativamente afetadas por ela. Sabemos muito sobre as mudanças nos postos de trabalho, nos requisitos de qualificação dos novos métodos de trabalho, nos processos de trabalho de uma maneira geral, nas relações industriais internas às plantas (as "políticas de produção"), nas formas de gestão do trabalho. Sabemos muito sobre como operam as novas 
tecnologias de base microeletrônica em vários setores produtivos, como mudaram as relações entre empresas, sobre as novas estratégias de mercado na nova ordem competitiva globalizada. Sabemos relativamente muito sobre as novas configurações dos mercados de trabalho, como as empresas combinam mercados internos e externos para otimizar o uso da força de trabalho. Sabemos que as novas tecnologias são poupadoras de mão-deobra e sabemos, tipicamente, quais novos requisitos os postos de trabalho reestruturados exigem do trabalhador. Mas sabemos pouco ou quase nada sobre alguns aspectos da vida produtiva desse trabalhador, ou melhor, temos sobre eles uma informação insuficiente, sobretudo porque restrita às ocupações que sobrevivem à reestruturação. Este trabalho tem como objetivo central desvendar parte deste mistério, com foco nas trajetórias profissionais dos trabalhadores das indústrias de material de transportes do Estado de São Paulo, que perderam ou que estavam sob risco de perderseu emprego no curso das políticas de reconversão tecnológica deste set.

Pode-se dizer que boa parte dos estudos sobre reestruturação produtiva postou-se nos chãos de fábrica, argüindo a tecnologia para buscar na organização social potencialidades ou limites à sua implantação ${ }^{1}$. Formulo numa frase a pergunta central que, tipicamente, os animou: dado que as empresas estão se reestruturando para competir, e dado que isto é um movimento inexorável na nova economia globalizada, que tipo de trabalhador atende aos requisitos dos novos processos produtivos? A pressuposição, sempre implícita, era a de que trabalhadores "adequados" encontrariam e sobreviveriam nos novos empregos gerados.

A perspectiva metodológica adotada aqui é diversa, ainda que em certo sentido complementar a esta abordagem. Cumpre argüir a estrutura mesma de oferta e demanda de força de trabalho para desvelar as potencialidades efetivas de incorporação produtiva e social dos trabalhadores que tiveram no mundo fabril seu projeto de emprego. A análise orientou-se por uma pergunta muito geral: se é verdade que a indústria automo- 
bilística se aproxima de uma reestruturação de tipo sistêmico, isto é, que atinge todos os elos da cadeia de produção e distribuição de seus produtos; se esta reestruturação tem como um de seus efeitos mais evidentes a destruição de postos de trabalho, com conseqüente demissão de grande número de trabalhadores e se isto ocorre num ambiente geral de redução do emprego industrial e aumento do desemprego estrutural, então parece estratégico argüir sobre o destino empregatício dos trabalhadores que estão perdendo seu emprego ali. Mais do que isso, é essencial desvendar porque determinados trabalhadores se encontram em posição mais frágil do que outros no mercado de trabalho.

Este problema genérico desdobra-se em questões mais específicas, destinadas à operacionalização empírica: se a obtenção de um emprego pode ser pensada como o cruzamento, de um lado, de estratégias e projetos de vida dos trabalhadores e, de outro, da disponibilidade objetiva de vagas no mercado (isto é, estratégias de produção dos empregadores), então qual o papel de cada elemento da equação na determinação das chances de permanência em (ou mudança de) uma condição qualquer, como o emprego ou o desemprego? Terão os trabalhadores suas estratégias de vida e emprego subordinadas à dinâmica alucinante da reestruturação ou, como quer a ideologia hegemônica nas análises econômicas sobre o mercado de trabalho, os indivíduos podem, individualmente, aumentar sua "empregabilidade" via melhoria de sua qualificação formal (escolaridade), por exemplo?

Como hipótese global de trabalho, parece plausível suspeitar que, quanto mais sistêmica a reestruturação de um setor qualquer, maiores os riscos de perda do emprego e menores as chances de reinserção profissional dos demitidos, de tal modo que se preservem o capital qualificacional e a qualidade de emprego de origem. Isto porque o risco ou a efetiva perda do emprego decorreria, sobretudo, da destruição de postos de trabalho (redundância) mercê da reestruturação produtiva, fruto do desaparecimento de funções, do redesenho de antigas tarefas, da fusão de outras, da 
terceirização de setores e fases dos processos de produção, etc. A demissão deveria representar, então exclusão do setor reestruturado.

Entretanto não é incorreto supor que essas chances não estejam distribuídas da mesma maneira entre todos. Se aos novos métodos de gestão e uso do trabalho, além das novas tecnologias, associam-se expectativas quanto à qualificação da força de trabalho que valorizam a educação formal, muito mais do que o treinamento e aprendizado on the job, então é possível esperar um aumento, no tempo, do papel da educação na explicação das chances de migração virtuosa, isto é, para um novo emprego formal. O risco de perda de emprego será, supõe-se, maior para os menos escolarizados, e serão piores suas chances de retorno. Do mesmo modo, como os custos de reconversão profissional são mais altos quanto mais velho o trabalhador, já que qualquer investimento pessoal terá retorno em tempo cada vez mais curto quanto mais se aproxima da idade de aposentarse, é de se esperar que os mais jovens tenham maiores chances tanto de permanecer no emprego quanto de migrar bem (para outro emprego formal), pelo inverso da mesma razão: seus investimentos individuais podem ser "colhidos" em tempo mais largo, reforçando o incentivo, imposto pelo mercado de força de trabalho, para que se (re)qualifiquem formalmente. Assim, também as mulheres terão, talvez, suas chances diminuídas, seja quanto à obtenção de um emprego qualquer, seja no que tange à probabilidade de migrar bem. Isto não decorrerá de qualquer inabilidade inata das mulheres por comparação com os homens, mas simplesmente da operação das hierarquias sociais mais gerais, que atribuem à mulher lugar subordinado.

Perguntas e hipóteses serão exploradas tendo como foco os trabaIhadores da indústria de material de transportes do Estado de São Paulo, com dados extraídos da Relação Anual de Informações Sociais - RAIS. Mais especificamente, utilizei uma base de dados experimental para análise de percursos no mercado formal de trabalho, denominada RAIS.TXT, produzida pelo Ministério do Trabalho no âmbito de um projeto de pesquisa larga- 
mente descrito em Castro, Cardoso e Caruso (1997) e financiado por CNPq, Finep, Faperj e Novib. Com base neste banco de dados, foi possível acompanhar o mesmo grupo de indivíduos em todos os seus vínculos no mercado formal de trabalho entre 1989 e 1995.

\section{Uma palavra sobre o método}

Método adequado de investigação do problema proposto é o de análise de história de eventos, aqui tratado por meio de técnica conhecida como "regressão de Cox", um instrumental estatístico poderoso e largamente hegemônico na literatura internacional sobre transições no mercado de trabalho. Originalmente desenvolvido para explicar a probabilidade temporalmente dependente de transição de um evento a outro, esse método é extremamente flexível, tendo aplicação em estudos de desemprego, de mobilidade ocupacional, de padrões de consumo, de saúde e medicina ou na pesquisa criminal, por exemplo (Courgeau, 1996b; Blossfeld e Rohwer, 1995; Mayer e Carroll, 1990; Mayer \& Tuma, 1990; Mayer e Huinink, 1990; Blossfeld, Hamerle e Mayer, 1989).

Embora o procedimento de Cox tenha o nome de regressão, na verdade é um instrumental semiparamétrico para estimação de funções de verossimilhança parcial. Ele procurará associar parâmetros a variáveis selecionadas, de tal modo que maximizem a probabilidade de encontrar o resultado que efetivamente já foi encontrado. Por outros termos, ele estima o risco de mudança de estado, como a demissão ou volta a um emprego formal e procura explicar (gerar parâmetros associados a variáveis) este risco, dadas as variáveis de interesse. A fórmula da taxa de risco a ser posteriormente estimada por verossimilhança parcial é dada por:

$R\left(m_{k}\right)=2 t_{k} / h_{k}\left(1+p_{k}\right)$,

onde R é a taxa de risco no intervalo de tempo k; t é probabilidade condicional de mudança de estado (perda do emprego, por exemplo) no 
intervalo k; h é o tamanho do intervalo k; e p é a proporção de indivíduos sobreviventes no intervalo k. A taxa deve ser lida como o risco instantâneo de mudança de estado num momento qualquer do tempo.

É importante salientar que o modelo de Cox requer que a razão entre as funções de risco de duas ou mais categorias na mesma população sejam proporcionais (não variem) no tempo. Por exemplo, no caso em discussão aqui, se tomo dois grupos de trabalhadores com escolaridade diversa, digamos, um grupo com menos que primeiro grau e outro com mais que primeiro grau, tenho que supor que a razão entre as funções de risco não muda no tempo: se a taxa de mortalidade (ou risco de demissão ou reemprego) dos menos escolarizados era 2 vezes maior do que a dos mais escolarizados no início, deve permanecer assim durante todo o período de 7 anos cobertos pela RAIS.TXT. Sobretudo, tenho que supor que o risco de perda ou de retorno a um emprego por parte dos trabalhadores menos escolarizados que entrem no mercado de trabalho hoje terá comportamento idêntico ao risco dos trabalhadores menos escolarizados há muito tempo no mercado.

Tais suposições são intuitivamente de difícil sustentação no que se refere à dinâmica do mercado de trabalho. Primeiro, porque as empresas mudam suas políticas de contratação e demissão ao longo do tempo, devido à introdução de novas tecnologias, de novas formas de gestão do trabaIho ou mesmo devido a transições demográficas. A massificação do ensino superior, por exemplo, tende a reduzir os custos de contratação de diplomados, estimulando a substituição de trabalhadores menos escolarizados. Isto afeta o risco de perda ou encontro de um novo emprego para ambos os grupos no tempo, de modo que o risco de demissão aumenta para os menos escolarizados relativamente aos diplomados (Pryor e Shaffer, 1999). Em segundo lugar, as pessoas ficam mais velhas. A idade pode ser tomada como indicador de experiência no mercado de trabalho e também de qualificação on the job, um tipo de investimento em capital humano que as empresas hesitarão em perder, preferindo demitir trabalhadores mais jo- 
vens. Trabalhadores mais velhos com pouca escolaridade serão, talvez, mais estáveis do que trabalhadores mais jovens de idêntica escolaridade, e esta diferença deve mudar no tempo quanto mais velhos eles se tornam. Os riscos, em lugar de proporcionais como supõe o modelo, tendem a aproximar-se quanto mais passa o tempo.

Embora importantes, estas objeções não têm impedido que esta metodologia seja amplamente hegemônica, em especial nas literaturas anglosaxônica, alemã e nórdica sobre trajetórias no mercado e trabalho (Baker e Elias, 1991; Blossfeld, Hamerle e Mayer, 1989; Mayer and Carroll, 1987; Featherman, 1986; Mayer and Tuma eds., 1990; dentre outros). Isto porque, segundo Allison (1984) e Mayer e Carroll (1987), os resultados continuam suficientemente robustos, mesmo na ausência de estrita proporcionalidade ${ }^{2}$, justificando o emprego da metodologia no estudo de transições no mercado de trabalho.

No que se segue, avaliarei o efeito da escolaridade, do sexo, da idade, da renda e da qualificação (variáveis relativas aos indivíduos), do setor e da região de origem das empresas (variáveis relativas ao empreendimento) sobre o risco instantâneo (no intervalo k) seja de voltar a um emprego formal tendo sido demitido, seja de ser demitido tendo conseguido um emprego formal, para os trabalhadores que tiveram algum vínculo em empresas de material de transportes no Estado de São Paulo em 1989. A base de dados compõe-se de quase 383 mil indivíduos que, sob qualquer parâmetro, devem ser tratados como o universo do emprego formal automobilístico paulista naquele ano, com o que se torna desnecessário construir testes estatísticos para a significância dos achados.

É importante salientar que impus uma restrição aos dados de origem: como estou interessado nos riscos de demissão e de retorno ao setor formal, mantive na análise apenas aqueles vínculos cujo resultado final te-

\footnotetext{
2 São possíveis vários testes de robustez. Dentre os mais importantes, está a comparação entre os coeficientes de regressão da amostra e os de uma subamostra homogênea. Por exemplo, se um teste de proporcionalidade (disponível em pacotes estatísticos como o SPSS e o SAS) revelar que uma população aparenta ter riscos diversos segundo a idade, é possível gerar regressões para cada estrato de idade isoladamente e depois comparar com o total da amostra.
} 
nha sido: (I) manutenção no emprego por todo o tempo; (II) demissão; ou (III) rescisão espontânea de contrato. Excluí os casos em que a perda de emprego, quando ocorreu, deveu-se a morte, aposentadoria/reforma, transferência, cessão ou "outros", todos eles motivos possíveis de mudança de estado conforme a RAIS. Não creio ser necessário justificar a exclusão dos casos de morte, já que esta é uma causa cabal. No caso de aposentadoria ou reforma, suponho que o trabalhador deixou a PEA, ainda que tal suposição não possa ser universalmente sustentada, sobretudo porque, no Brasil, as aposentadorias são muito baixas e raramente garantem a sobrevivência dos indivíduos. Mas, na explicação das chances de demissão, a aposentadoria tem o mesmo valor teórico da morte, já que também se impõe de forma natural, independentemente de outras injunções e, do ponto de vista da empresa, de forma relativamente irrecorrível, mesmo que ela possa eventualmente negociar com o trabalhador o adiamento do desligamento formal. Já cessão ou transferência não configura perda de emprego, apenas mobilidade horizontal na mesma empresa ou entre unidades da empresa. O interesse aqui não é a mobilidade intrafirma, e sim a mobilidade no mercado de trabalho. Essas restrições reduzem o total de casos a pouco menos de 356 mil pessoas.

Explicando as chances de demissão e admissão

Dito isso, iniciemos pelos que estavam empregados em 1989 analisando a Tabela 1. A primeira linha traz informações sobre o primeiro vínculo do indivíduo, a segunda sobre o segundo (obviamente, apenas para os que o tiveram) e assim por diante, até o décimo vínculo. A tabela permite afirmar que, do total de empregados em 1989 no setor formal (não importa se em um emprego em material de transportes ou não neste primeiro vínculo) ou mais de 355 mil indivíduos, 71,7\% perderam o emprego até 1995. Do segundo ao quarto vínculos, essa taxa iguala ou supera os $75 \%$, 
voltando à casa dos $71 \%$ em seguida. Impressiona quão constante é a taxa de demissão em cada vínculo, aspecto a ser melhor tratado em seguida.

A última coluna da tabela revela que a taxa de retorno a um novo emprego formal após uma demissão é também bastante alta, sempre superior a $70 \%$. Isto é, dos $71,7 \%$ que perderam o primeiro emprego (ou 254.990 pessoas), 71,6\% (ou 182.568 indivíduos) conseguiram outra ocupação. Dos pouco mais de 142 mil que perderam o segundo emprego, quase $110 \mathrm{mil}$ conseguiram novo vínculo formal (ou mais de 77\%), e assim por diante. Apesar das altas taxas de retorno, porém, a cada nova demissão entre 25\% e $30 \%$ dos trabalhadores não voltam, isto é, a proporção de trabalhadores que vai ficando pelo caminho com as demissões é relativamente constante no tempo, o que redunda em cada vez menos pessoas empregadas quanto maior o número de vínculos.

Tabela 1:

Número de vínculos e probabilidade de demissão e de retorno em cada um.

São Paulo, 1989-1995

\begin{tabular}{|c|c|c|c|c|c|}
\hline \multirow{2}{*}{ Evento } & \multicolumn{2}{|c|}{ Foi demitido } & N & Demitidos & Taxa de \\
\cline { 2 - 3 } & Não & Sim & & & reemprego \\
\hline Primeiro emprego & 28,32 & 71,68 & 355.750 & 254990 & 71,60 \\
\hline Segundo emprego & 22,15 & 77,85 & 182.568 & 142135 & 77,19 \\
\hline Terceiro emprego & 23,55 & 76,45 & 109.711 & 83870 & 77,26 \\
\hline Quarto emprego & 25,68 & 74,32 & 64.797 & 48155 & 76,39 \\
\hline Quinto emprego & 27,24 & 72,76 & 36.788 & 26767 & 75,76 \\
\hline Sexto emprego & 28,13 & 71,87 & 20.280 & 14576 & 74,57 \\
\hline Sétimo emprego & 28,28 & 71,72 & 10.869 & 7795 & 75,50 \\
\hline Oitavo emprego & 27,07 & 72,93 & 5.885 & 4292 & 73,09 \\
\hline Nono emprego & 26,52 & 73,48 & 3.137 & 2305 & 74,19 \\
\hline Décimo emprego & 25,61 & 74,39 & 1.710 & 1272 & 77,59 \\
\hline
\end{tabular}

Fonte: RAIS.TXT/MTb-Codefat

(*) Não perfaz $100 \%$ porque só considerei os primeiros 10 vínculos 
Dizer que a grande maioria das pessoas perderá o emprego não é dizer muito. Era de se esperar, dadas as altas taxas de rotatividade no Brasil. A surpresa está em que as chances de perder o emprego ou de retornar a um posto formal são praticamente constantes a cada vínculo. Para um indivíduo qualquer, em média para todo vínculo, a chance de perdê-lo é 2,8 vezes maior do que a chance de mantê-lo, ao passo que a chance de retorno de um demitido é 3 vezes maior do que a de permanecer fora do setor formal. Tanto a condição de empregado quanto a de excluído do setor formal são transitórias, se bem que, como perto de $1 / 4$ dos trabalhadores nunca retornam a cada nova demissão, acumula-se um passivo a cada vez, que, ao final, redunda na exclusão pura e simples, em 7 anos, de metade dos empregados em 1989.

Estes achados parecem contra-intuitivos. Parecem porque os processos sociais, normalmente, marcam-se por certa estabilidade e inércia que atualizam constantemente mecanismo análogo à cadeia de Markov, segundo o qual, num ponto qualquer no tempo, a probabilidade de permanência em determinado estado é sempre maior do que a de saída dele ${ }^{3}$. É o que nas análises longitudinais se denomina "dependência de estado" ${ }^{4}$. Quando tais processos envolvem instituições mais ou menos estáveis, como o são as empresas, a inércia se reveste de determinantes ainda mais poderosos, relacionados, antes de tudo, mas não unicamente, é claro, com compromissos quanto à sobrevivência do empreendimento no tempo, condição para a possível valorização do capital investido. Obviamente, manter o mesmo corpo de trabalhadores não tem relação direta com o desiderato de manutenção da empresa no tempo. A reestruturação econômica pode implicar exatamente o inverso. Mas se o investimento em "recursos humanos" é, e deve ser,

\footnotetext{
3 Na verdade, a dependência markoviana significa que, num intervalo de tempo suficientemente curto, a probabilidade de permanência no estado é sempre maior do que a de entrada nele a partir de qualquer outro estado. Logo, como isso vale para todos os estados num tempo qualquer, inclusive para o de referência (a partir do qual se entraria em outro estado qualquer), posso formulá-la nos termos que aparecem no texto, isto é, em termos da probabilidade de saída.

4 Ver Allison (1984); Blossfeld (1987a); Allmendiger (1991); Mayer e Tuma (1990); Elias (1994); Blossfeld e Rohwer (1995).
} 
encarado, do ponto de vista da empresa, como investimento de capital, um custo de produção que terá retorno esperado e computável em termos de produtividade do trabalho, então, tudo o mais permanecendo constante, é de se esperar a vigência plena do referido mecanismo markoviano, e a inércia deveria imperar sobre a mudança. As altas taxas de mudança estariam revelando ausência de dependência de estado no mercado de trabalho paulista.

Aqui é preciso cautela. Estamos tratando de um setor econômico que passou por intensos processos de reestruturação produtiva na primeira metade da década de 90. Logo, mudanças na configuração da força de trabalho e nas chances de permanência em determinado estado (emprego ou exclusão, não importa) eram esperadas. A surpresa, como mencionado, decorre da relativa estabilidade das taxas de retorno e demissão, que parecem inteiramente independentes do número de eventos. Ora, se a mudança de estado é a regra, isto não quer necessariamente dizer que a probabilidade de mudança seja maior do que a de permanência num dado momento no tempo. No agregado, isto é, no período de 7 anos considerado, é mais provável que se mude do que se permaneça na mesma condição. Mas num ponto qualquer no tempo, talvez isso não seja verdade. Torna-se questão relevante investigar, então, até que ponto a mudança ocorre numa dinâmica temporal diversa segundo os vários vínculos. Ademais, é preciso saber qual o impacto do transcurso do tempo sobre as chances de permanência ou mudança de estado. Só então será possível dizer com segurança estarmos diante de negação do que a literatura pertinente assegura ser característica marcante da dinâmica dos mercados de trabalho, isto é, a dependência de estado.

Nesta ordem de razões, a Tabela 2 mostra que as médias tanto de tempo de emprego quanto de tempo de exclusão do setor formal são menores a cada novo evento. Isto quer dizer, simples- 
mente, que os processos em análise não são independentes do número de eventos, de sorte que este afeta decisivamente as chances de permanência ou mudança. Ou seja, a mudança de estado ocorre a intervalos cada vez menores quanto mais o indivíduo muda de estado, o que é o mesmo que dizer que o tempo de permanência é cada vez menor quanto maior o número de empregos de cada indivíduo.

Tabela 2

Médias de permanência em cada estado, segundo os vínculos até o décimo

\begin{tabular}{|c|c|c|}
\hline \multirow{2}{*}{ Evento } & $\begin{array}{c}\text { Tempo até } \\
\text { demissão }\end{array}$ & $\begin{array}{c}\text { Tempo fora } \\
\text { formal }\end{array}$ \\
\cline { 2 - 3 } & \multicolumn{2}{|c|}{ Em meses } \\
\hline Primeiro emprego & 39 & 20 \\
\hline Segundo emprego & 21 & 15 \\
\hline Terceiro emprego & 16 & 12 \\
\hline Quarto emprego & 13 & 10 \\
\hline Quinto emprego & 11 & 9 \\
\hline Sexto emprego & 9 & 8 \\
\hline Sétimo emprego & 8 & 7 \\
\hline Oitavo emprego & 7 & 6 \\
\hline Nono emprego & 7 & 6 \\
\hline Décimo emprego & 6 & 5 \\
\hline Tempo médio & $\mathbf{2 6}$ & $\mathbf{1 6}$ \\
\hline
\end{tabular}

Fonte: RAIS.TXT/MTb-Codefat

Embora este achado seja intuitivamente evidente (num tempo finito, um número maior de eventos significa menor duração média para cada evento), não resulta necessariamente nos movimentos perceptíveis nos Gráficos 1e 2, que trazem novas luzes sobre a relação entre dependência de estado e dependência de even- 
to nos processos em apreço.

Pelo Gráfico 1 fica evidente que, ao final de 6 meses, a probabilidade cumulativa de permanência fora do setor formal era praticamente a mesma para todas as 5 primeiras demissões, ou em torno de $68 \%$. Isso é o mesmo que dizer que, no transcurso de 6 meses, a probabilidade cumulativa de retorno a um emprego formal era de perto de $32 \%$, para todo e qualquer dos 5 primeiros vínculos. A partir daí, entretanto, as curvas passam a se distanciar. Em 12 meses, a chance de retorno dos que sofreram a primeira demissão era de $50 \%$, contra $60 \%$ dos que sofreram a segunda e $70 \%$ dos que foram demitidos pela quinta vez. Não se está falando de tempos médios como antes. Trata-se efetivamente da mensuração da dependência de estado a cada evento, e o que está sendo demonstrado é que essa dependência, conquanto exista ${ }^{5}$, é cada vez menor, porque o tempo transcorrido no mesmo estado - no caso, exclusão do setor formal - é cada vez menor, não em razão da lógica dos números (tempo finito e número de eventos determinando a média de tempo), mas em razão da lógica do mercado de trabalho: indivíduos que rodam mais têm mais chances de retornar a um novo emprego em um tempo mais curto do que os que rodam menos. Aparentemente tautológica, esta afirmação tem conseqüências de monta para a análise das chances de emprego da população assalariada e, obviamente, para o debate corrente no Brasil em torno do problema da "empregabilidade", termo ambíguo ao qual voltarei.

\footnotetext{
5 Veja-se que, quanto mais tempo o indivíduo permanece fora do setor formal, menor a taxa de retorno. Isto é, para o primeiro evento, se a probabilidade de retorno em 12 meses era de cerca de $50 \%$, daí até o final dos 12 meses seguintes tinha caído para perto de 5\%, e para menos de 3\% nos 12 meses seguintes.
} 


\section{Gráfico1:}

Função de retorno ao mercado de trabalho, segundo os vínculos. Estado de São Paulo, 1989-1995

\section{Grafico 1}

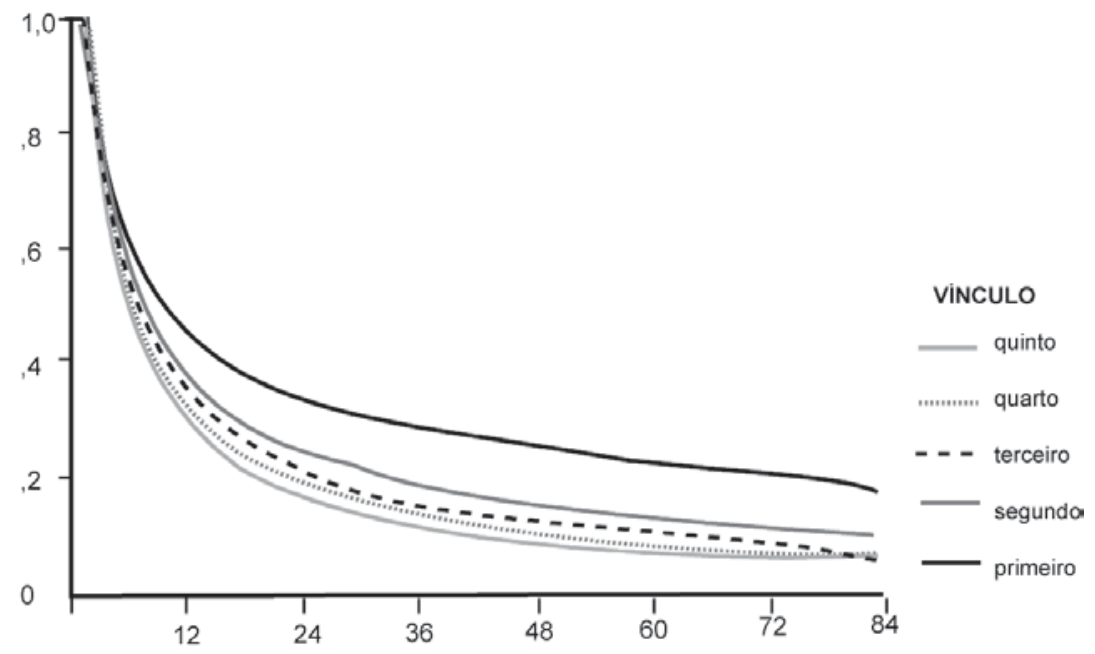

Fonte: RAIS.TXT-MTb/Codefat

O Gráfico 2 representa as chances de os empregados sobreviverem em cada vínculo até o quinto, e os padrões são muito semelhantes ao que se discutiu antes: a probabilidade de sobrevivência no primeiro estado (neste caso, no primeiro emprego em 1989) é mais intensamente dependente do tempo do que no caso dos vínculos subseqüentes. Ao final de 12 meses, por exemplo, aquela probabilidade era de perto de $70 \%$, contra $55 \%$ no segundo e $40 \%$ no quinto empregos. Ao fim de 24 meses, a chance dos que tiveram o quinto emprego continuarem empregados era de apenas $20 \%$, 
contra mais de $50 \%$ daqueles em primeira ocupação. Em todos os casos, porém, o processo parece dependente do tempo: quanto mais o indivíduo permanece no emprego, menores as chances de que seja demitido, situação mais intensa para o primeiro vínculo. Finalmente, em acordo com o que se disse a respeito do gráfico anterior, cada novo vínculo aumenta muito as chances de demissão.

\section{Gráfico 2:}

Função de sobrevivência no emprego, segundo o vínculo. Estado de São Paulo, 1989-1995

\section{Grafico 2}

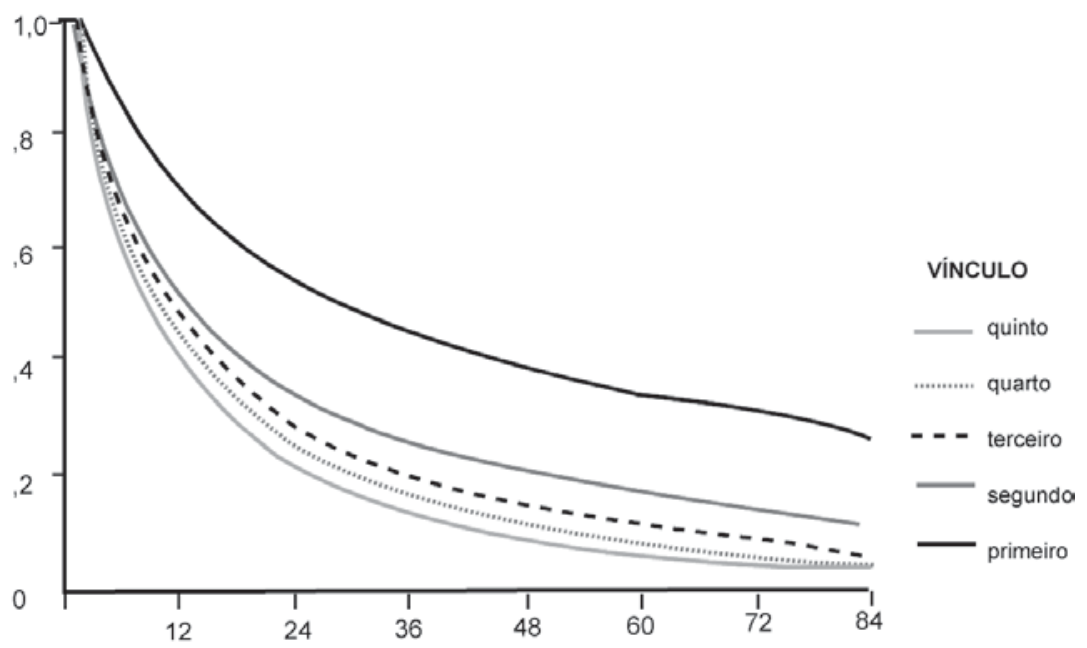

Fonte: RAIS.TXT-MTb/Codefat 
Vistos em conjunto, os gráficos estão sugerindo que a perda de um emprego é mais provável quanto mais o trabalhador rode entre empregos e que, de forma correlata, o retorno a um emprego é mais provável entre os trabalhadores que também rodam muito. Portanto, se há uma nítida e decrescente dependência de estado em todos os eventos, é no primeiro que encontrar-se empregado aumenta substancialmente as chances de permanência neste estado quanto mais passa o tempo. Do mesmo modo, encontrar-se desempregado aumenta as chances de continuar neste estado quanto mais passa o tempo, processo mais intenso no caso da primeira demissão. Nas demais, uma nova perda de emprego é crescentemente garantia de um novo emprego e, portanto, de mudança de estado.

Ora, a Tabela 1 nos revelou que as taxas de demissão ou retorno não são muito diversas segundo os vínculos. Cedo ou tarde, entre 71\% e 77\% dos trabalhadores perderão o emprego e entre 71 e $77 \%$ voltarão ao setor formal. O que varia é o tempo de sobrevivência no emprego ou de espera fora do setor formal. Mas parece evidente que os indivíduos se tornam cada vez mais "empregáveis" ("empregabilidade" definida aqui em termos da probabilidade temporalmente dependente de retorno a um posto qualquer de trabalho formal) quanto mais vezes percam seus empregos. Isso porque cada novo desemprego reduz o tempo de espera fora do setor formal. Mas cada novo emprego reduz também o tempo de sobrevivência nele, ainda que isto não tenha qualquer impacto, ou tenha impacto muito reduzido sobre as taxas finais de retorno.

Se isso é verdade, é questão relevante investigar as razões para tais chances diferenciais de demissão e retorno. Qual o papel das características da oferta e da demanda por trabalho neste resultado? Desdobramento necessário será inquirir por que alguns trabalhadores voltam, mas perdem o novo emprego, aumentando, assim, as chances de novo retorno e nova demissão, isto é, alimentando os processos mais largos de rotatividade de força de trabalho. Vejamos 


\section{Demissão e retorno}

A base de dados RAIS.TXT permite lançar mão de uma série de indicadores válidos como variáveis independentes em modelos causais, caso da idade, do sexo, da escolaridade e da qualificação do indivíduo, dentre outras importantes. É claro que esses indicadores não foram desenhados especificamente para este tipo de análise, assim como não há garantias de que eles controlem adequadamente, pela heterogeneidade da força de trabalho. Pode haver, e certamente haverá, dimensões não mensuradas que sejam tão ou mais importantes na explicação dos eventos em questão do que os indicadores disponíveis. Vale a pena esclarecer este ponto antes de continuar.

A literatura especializada sobre migrações no mercado de trabalho põe ênfase em, pelo menos três, aspectos salientes do curso de vida das pessoas que não constam da RAIS.TXT: a trajetória migratória (geográfica), a trajetória nupcial e as estratégias reprodutivas dos casais (Featherman, 1986; Blossfeld, 1987a e 1987b; Featherman, Salbee e Mayer 1989; Allmendinger, 1989; Mayer \& Tuma, 1990; Walby, 1991; Auriat, 1993; Elias, 1994; Barbary, 1996). Trabalhadores mudam de cidade por várias razões: para acompanhar os pais ou cônjuges, para estudar, para juntar-se a parentes que migraram antes, etc. Se estamos falando de trabalhadores, é provável que o substrato de qualquer desses processos seja ou a perda de um emprego ou a oferta de outro melhor. Logo, migrações geográficas, em geral fruto de longa maturação individual conjugada com estratégias familiares mais gerais, podem ser tanto resultado quanto causa da mudança de condição de atividade (emprego ou desemprego), constituindo-se em indicador necessário em análises de mobilidade ocupacional que pretendam estabelecer os componentes causais das probabilidades de transição, como é o caso aqui.

Já a nupcialidade tem impactos importantes sobre as trajetórias ocupacionais de mulheres e, menos intensamente, de homens. A redução das disparidades de gênero no mundo contemporâneo, se bem que inten- 
sa, não se efetivou por completo, e o casamento ainda é, para parte expressiva das mulheres e segundo dinâmica diversa conforme a classe social, um rito de passagem que redireciona suas opções de vida para os horizontes restritos do universo doméstico, por oposição ao mundo do trabalho. As crescentes taxas de participação das mulheres no Brasil, que pularam da faixa dos 30\% para perto dos 50\% daquelas em idade ativa, entre as décadas de 80 e 90 segundo dados da PNAD, não são ainda suficientes para a reversão do papel central do homem como provedor do lar, em relação ao qual os projetos femininos se constroem, de forma quase sempre subordinada $^{6}$.

Por fim, o nascimento de filhos compromete, em geral inapelavelmente, os percursos ocupacionais das mulheres, embora afete também a trajetória dos homens, se bem que a taxas muito menos intensas. Para as mulheres, a natividade implica um compromisso físico e emocional sem paralelos no gênero oposto e, não raro, a licença maternidade se acompanha de abandono ou troca de emprego em favor, por exemplo, de ocupações menos demandantes ou autônomas, em período não regular ou em meia jornada, etc., que possibilitem amamentar e/ou acompanhar o crescimento inicial dos filhos.

Estes três elementos da biografia dos indivíduos estão mais ou menos diretamente relacionados com as escolhas ocupacionais ao longo da vida. Logo, no que se segue, o leitor deve ter em conta a possibilidade muito real de que parte substancial dos mecanismos causais subjacentes que contribuem para a explicação dos processos temporais avaliados não foi mensurada pela RAIS.TXT.

Ainda assim, os indicadores disponíveis produziram estatísticas suficientemente significativas para sustentar sua utilização como medidas válidas, ainda que não exaustivas, dos referidos processos causais subjacentes às trajetórias individuais no mercado formal de trabalho paulista. Vejamos. 


\section{Riscos de mudança de estado}

O modelo de riscos proporcionais de Cox permite uma apreensão bastante eficiente da direção dos efeitos de cada variável sobre as taxas de mortalidade e retorno a um emprego formal, bem como de sua intensidade em termos percentuais. Nas tabelas 3 e 4 apresento apenas o efeito líquido de cada variável, já que, como estou trabalhando, em tese, com o universo dos trabalhadores formais, não faz sentido falar em significância estatística dos coeficientes. Os valores apresentados referem-se à mudança percentual na taxa instantânea de risco de mudança de estado (perda de emprego ou retorno ao setor formal) provocada pelo aumento de uma unidade na variável independente ou, no caso das variáveis dummy, pela ocorrência da situação (ser ou não homem por oposição às mulheres, ter ou não ginásio por oposição a ter primário completo etc.).

Podem-se resumir as Tabelas 3 e 4, em suas grandes linhas, em algumas poucas frases:

a.) Os determinantes dos riscos de demissão e de retorno têm peso explicativo diverso a cada vínculo. Não é indiferente ter um, dois ou três empregos no período, do ponto de vista das causas da mudança de estado;

b.) A qualificação, mesmo se mensurada pela renda ${ }^{7}$, tem enorme poder explicativo global, sobretudo da demissão, se bem que cadente a cada vínculo. No caso do risco de demissão, ela interfere decisivamente no impacto independente das demais variáveis, em geral reduzindo-os de forma substancial. Ela chega mesmo a inverter o sinal da influência da esco-

\footnotetext{
7 A medida de qualificação utilizada é fruto da multiplicação do tempo de emprego em meses pela renda real média mensal no ano da demissão. Esta interação tende a corrigir as deficiências da renda e do tempo de emprego quanto tomados isoladamente como medida de qualificação, já que indivíduos muito estáveis podem ter renda muito baixa (copeiros, por exemplo), e indivíduos instáveis podem ser muito qualificados (altos executivos disputados por empresas). Para evitar que alta renda e longa permanência "puxe" a média da distribuição, nas tabelas transformei a variável em vintis de sua distribuição. Cada ponto na escala de qualificação engloba 5\% da população. No caso do risco de demissão, tive que me ater à renda como proxida qualificação, já que o tempo de emprego está autocorrelacionado com a variável dependente. Discuto longamente os critérios de criação desta variável em Cardoso (2000: cap. 3).
} 
laridade. Mais importante do que isso, sua introdução melhora sensivelmente a adequação dos modelos aos dados;

c.) A idade é sempre importante, mas as diferenças entre os estratos perdem intensamente poder explicativo quanto mais os indivíduos rodem entre empregos, especialmente no que tange às chances de retorno e perdem mais ainda quando consideramos a qualificação;

d.) Antes do controle pela qualificação, a escolaridade tem efeito crescente, isto é, as diferenças de grau escolar têm impacto cada vez maior na explicação do retorno e decrescente na explicação da demissão, quanto maior o número de vínculos;

e.) Tudo o mais permanecendo constante, os homens perdem emprego mais cedo, mas por outro lado voltam mais rapidamente ao setor formal do que as mulheres, diferença que tem menos importância a cada novo vínculo;

f.) A estrutura do mercado de trabalho, medida pelo setor e pelo tamanho do mercado formal de trabalho do município de origem, contribui muito pouco para explicar os riscos de mudança de estado, se bem que há diferenças importantes entre risco de demissão e de retorno;

g.) Os modelos são robustos, sobretudo na explicação do risco instantâneo de demissão, robustez reduzida a cada novo evento. No caso do retorno a um posto formal, só explicam adequadamente o primeiro evento. É o que nos informam as linhas " $\mathrm{R}^{2}$ " em cada porção das tabelas ${ }^{8}$. Avaliemos cada um desses achados em maior detalhe.

8 O R2 utilizado aqui como medida de adequação (goodness of fit) dos modelos é uma adaptação do índice proposto por Estrella (1998) para modelos logísticos de máxima verossimilhança (likelihood) com variáveis dependentes dicotômicas. Trata-se de uma aproximação à adequação, não uma medida incontestável, sobretudo porque a variável dependente aqui é a taxa de mortalidade ou o risco de mudança de estado no tempo. Entretanto, como a fórmula empregada é a mesma em todos os casos, serve para mostrar a mudança na capacidade explicativa de um evento a outro e para comparar a robustez dos diversos modelos propostos. O R2 é dado por: [1 - ( $\left(\log \mathrm{L}_{\mathrm{u}}\right.$ $\left.\left.\left.-k / \log L_{c}\right)-(2 / n) \log L c\right)\right]$, onde $L_{u}=$ likelihood dos modelos sem variáveis; $L_{c}=$ likelihood dos modelos com as variáveis; e k são os graus de liberdade dos modelos. Segundo Estrella, esta é a única medida de adequação de modelos de máxima verossimilhança que cumpre os requisitos de um R2 tradicional (gerado em regressões lineares), servindo como medida análoga: (i) a medida toma valores entre 0 e 1 , em que 0 corresponde a nenhuma adequação e 1 a adequação completa; (ii) baseia-se numa estatística válida para o teste da hipótese de que os coeficientes de todas as variáveis explicativas, com exceção da constante, é zero; (iii) e a derivada da medida com respeito à estatística de teste está em acordo com a derivada correspondente nos modelos lineares. 


\section{Tabela 3:}

Resultados de estimação do modelo de Cox para o risco de demissão dos trabalhadores que tiveram algum vínculo formal em setores de material de transportes, segundo os primeiros cinco vínculos: modelos com e sem qualificação, Estado de São Paulo, 1989-1995

\begin{tabular}{|c|c|c|c|c|c|}
\hline \multirow{2}{*}{$\begin{array}{l}\text { Risco de demissão } \\
\text { Modelo sem renda }\end{array}$} & \multicolumn{5}{|c|}{ Eventos } \\
\hline & 1o evento & 20 evento & 3o evento & 4o evento & 50 evento \\
\hline \multicolumn{6}{|c|}{ Idade (ref. $=50$ anos ou mais) } \\
\hline Até 17 anos & 410,78 & 283,39 & 271,50 & 229,60 & 160,05 \\
\hline 18 а 24 & 288,76 & 193,80 & 160,17 & 140,36 & 111,62 \\
\hline 25 a 29 & 131,49 & 74,92 & 62,96 & 54,74 & 43,35 \\
\hline 30 a 39 & 33,81 & 41,06 & 41,56 & 43,48 & 37,14 \\
\hline 40 a 49 & $-15,63$ & 11,38 & 23,26 & 26,82 & 24,21 \\
\hline Sexo masculino & $-4,67$ & 3,48 & 4,84 & 7,08 & 4,11 \\
\hline \multicolumn{6}{|c|}{ Escolaridade (ref.=Primário Completo) } \\
\hline Ginásio & $-17,08$ & $-16,14$ & $-10,92$ & $-7,77$ & $-5,97$ \\
\hline Colegial & $-31,23$ & $-25,04$ & $-23,08$ & $-19,14$ & $-18,84$ \\
\hline Superior & $-34,49$ & $-30,21$ & $-33,15$ & $-34,53$ & $-41,06$ \\
\hline \multicolumn{6}{|c|}{ Tamanho do setor formal do município (ref.= até 100 mil trab.) } \\
\hline $101 \mathrm{mil} \mathrm{a} 500 \mathrm{mil}$ & $-10,93$ & $-4,99$ & 3,77 & 7,50 & 6,04 \\
\hline 501 mil ou mais & 27,09 & 5,91 & 2,32 & $-1,33$ & $-4,53$ \\
\hline $\begin{array}{l}\text { Índice de Qualidade } \\
\text { de Emprego }\end{array}$ & 2,27 & 2,50 & 2,31 & 2,48 & 2,36 \\
\hline Casos sem informação & 4439 & 3997 & 2644 & 1736 & 1006 \\
\hline Casos válidos & 351311 & 178571 & 107067 & 63061 & 35782 \\
\hline $\mathbf{R}^{2}$ & 0,426 & 0,290 & 0,218 & 0,195 & 0,165 \\
\hline Modelo com renda & $1 \mathrm{o}$ evento & 2 o evento & 30 evento & 4o evento & 5o evento \\
\hline \multicolumn{6}{|c|}{ Idade (ref. $=50$ anos ou mais) } \\
\hline até 17 anos & 67,65 & 110,5 & 134,46 & 138,09 & 93,75 \\
\hline 18 а 24 & 103,95 & 110,96 & 104,51 & 97,76 & 78,18 \\
\hline 25 a 29 & 69,31 & 57,28 & 50,48 & 44,03 & 35,7 \\
\hline 30 a 39 & 28,59 & 43,5 & 44,52 & 44,57 & 40,36 \\
\hline 40 a 49 & $-5,32$ & 22,38 & 32,93 & 34,42 & 34,36 \\
\hline Sexo masculino & 31,89 & 29,88 & 26,13 & 25,45 & 18,61 \\
\hline \multicolumn{6}{|c|}{ Escolaridade (ref.=Primário Completo) } \\
\hline Ginásio & 1,46 & $-1,6$ & 1,34 & 3,32 & 6,18 \\
\hline Colegial & 13,33 & 10,14 & 6,43 & 8,32 & 7,71 \\
\hline Superior & 32,24 & 22,66 & 14,2 & 3,34 & $-8,12$ \\
\hline \multicolumn{6}{|c|}{ Tamanho do setor formal do município (ref.= até 100 mil trab.) } \\
\hline 101 mil a 500 mil & 6,15 & 10,05 & 13,35 & 15,36 & 13,08 \\
\hline 501 mil ou mais & 23,18 & 11,5 & 6,25 & 2,19 & $-1,11$ \\
\hline $\begin{array}{l}\text { Índice de Qualidade } \\
\text { de Emprego }\end{array}$ & 1,05 & 1,32 & 1,45 & 1,73 & 1,74 \\
\hline Renda real em vintis & $-12,75$ & $-10,65$ & $-9,18$ & $-8,24$ & $-7,75$ \\
\hline Casos sem informação & 4439 & 3997 & 2644 & 1736 & 1006 \\
\hline Casos válidos & 351311 & 178571 & 107067 & 63061 & 35782 \\
\hline $\mathbf{R}^{2}$ & 0,636 & 0,508 & 0,394 & 0,336 & 0,288 \\
\hline
\end{tabular}


Sociologias, Porto Alegre, ano 2, no 4, jul/dez 2000, p.144-185

\section{Tabela 4:}

Resultados de estimação do modelo de Cox para o risco de retorno dos trabalhadores demitidos que tiveram algum vínculo formal em setores de material de transportes, segundo os primeiros cinco vínculos: modelos com e sem qualificação, Estado de São Paulo, 1989-1995

\begin{tabular}{|c|c|c|c|c|c|}
\hline \multirow{2}{*}{$\begin{array}{l}\text { Risco de demissão } \\
\text { Modelo sem renda }\end{array}$} & \multicolumn{5}{|c|}{ Eventos } \\
\hline & 1o evento & 20 evento & 3o evento & 4o evento & 5o evento \\
\hline \multicolumn{6}{|c|}{ Idade (ref. $=50$ anos ou mais) } \\
\hline até 17 anos & 339,77 & 81,66 & 31,11 & 14,02 & 9,1 \\
\hline 18 a 24 & 453,82 & 142,83 & 70,45 & 43,92 & 30,78 \\
\hline 25 a 29 & 389,03 & 128,25 & 64,49 & 40,58 & 25,52 \\
\hline 30 a 39 & 328,08 & 119,69 & 68,43 & 44,03 & 31 \\
\hline 40 a 49 & 177,78 & 83,1 & 52,4 & 34,95 & 25,6 \\
\hline Sexo masculino & 48,2 & 38,68 & 35,27 & 34,95 & 29,07 \\
\hline \multicolumn{6}{|c|}{ Escolaridade $($ ref. $=$ Primário Completo $)$} \\
\hline Ginásio & $-0,82$ & 1,45 & 6,3 & 8,71 & 8,97 \\
\hline Colegial & $-2,31$ & 2,78 & 7,35 & 14,07 & 15,12 \\
\hline Superior & 1,8 & $-4,59$ & 5,55 & 13,13 & 15,77 \\
\hline \multicolumn{6}{|c|}{ Tamanho do setor formal do município (ref. = até 100 mil trab.) } \\
\hline $101 \mathrm{mil} \mathrm{a} 500 \mathrm{mil}$ & $-4,83$ & $-2,41$ & 0,83 & 2,8 & 2,6 \\
\hline 501 mil ou mais & 4,65 & $-2,22$ & $-4,17$ & $-7,13$ & $-8,06$ \\
\hline $\begin{array}{l}\text { Índice de Qualidade } \\
\text { de Empregao2,86 }\end{array}$ & 0,51 & 0,42 & 0,42 & 0,29 & \\
\hline Casos sem informação & 13385 & 5505 & 3240 & 2027 & 1188 \\
\hline Casos válidos & 241605 & 136630 & 80630 & 46128 & 25579 \\
\hline $\mathbf{R}^{2} 0,259$ & 0,056 & 0,026 & 0,022 & 0,015 & \\
\hline Modelo com qualif. & 10 evento & $2^{o}$ evento & $3^{\circ}$ evento & $4^{o}$ evento & 5o evento \\
\hline \multicolumn{6}{|c|}{ Idade (ref. $=50$ anos ou mais) } \\
\hline até 17 anos & 192,03 & 55,72 & 18,47 & 7,42 & 4,13 \\
\hline 18 а 24 & 303,00 & 120,50 & 61,42 & 39,17 & 27,63 \\
\hline 25 a 29 & 282,87 & 115,70 & 59,66 & 38,33 & 24,17 \\
\hline 30 а 39 & 265,24 & 111,00 & 65,48 & 42,65 & 30,29 \\
\hline 40 a 49 & 163,54 & 80,01 & 51,51 & 34,72 & 25,76 \\
\hline Sexo masculino & 53,90 & 42,17 & 37,29 & 36,49 & 30,55 \\
\hline \multicolumn{6}{|c|}{ Escolaridade $($ ref. $=$ Primário Completo $)$} \\
\hline Ginásio & 3,14 & 4,18 & 7,84 & 9,82 & 9,76 \\
\hline Colegial & 8,68 & 9,67 & 11,70 & 16,80 & 17,43 \\
\hline Superior & 22,68 & 7,99 & 14,09 & 19,29 & 21,63 \\
\hline \multicolumn{6}{|c|}{ Tamanho do setor formal do município (ref.= até 100 mil trab.) } \\
\hline $101 \mathrm{mil} \mathrm{a} 500 \mathrm{mil}$ & $-1,98$ & $-0,45$ & 1,36 & 3,06 & 3,01 \\
\hline 501 mil ou mais & 3,21 & $-0,96$ & $-3,40$ & $-6,59$ & $-7,43$ \\
\hline $\begin{array}{l}\text { Indice de Qualidade } \\
\text { de Emprego }\end{array}$ & 2,26 & 0,17 & 0,23 & 0,30 & 0,19 \\
\hline Qualificação em vintis & $-4,57$ & $-2,71$ & $-1,70$ & $-1,17$ & $-0,98$ \\
\hline Casos sem informação & 13385 & 5505 & 3240 & 2027 & 1188 \\
\hline Casos válidos & 241605 & 136630 & 80630 & 46128 & 25579 \\
\hline $\mathbf{R}^{2} 0,303$ & 0,079 & 0,037 & 0,028 & 0,020 & \\
\hline
\end{tabular}

Fonte: RAIS.TXT-MTb/Codefat 
(a) Pela análise nas seções anteriores, sabemos que cada novo emprego formal reduz o tempo, mas não as chances de permanência nele, e que cada nova demissão reduz o período de espera por um novo posto formal. Agora, fica claro que as características da força de trabalho e do mercado de trabalho contribuem de forma diversa a cada vínculo, isto é, a explicação para o tempo transcorrido até a mudança de estado não é a mesma a cada vez. Aquelas características perdem poder explicativo a cada novo evento, sugerindo que o mercado de trabalho paulista é seletivo pelo lado da demanda, pois parece impor limites e restrições ao percurso ocupacional que são dependentes do número de eventos. Voltarei a isso.

(b) A renda e a qualificação em vintis revelam-se determinantes poderosos do risco de migração, sobretudo no que se refere à perda do emprego formal. Cada vintil na escala de renda reduz em quase 13\% o risco instantâneo de demissão ou a taxa de mortalidade no primeiro evento da janela observacional, efeito que, se cai a menos de $8 \%$ no quinto emprego, ainda assim continua elevado.

É preciso lembrar que os parâmetros numa regressão se referem ao efeito médio do acréscimo de uma unidade na variável independente e não a um efeito uniforme, no caso em tela, por vintil. De qualquer modo, se o efeito fosse uniforme, tudo o mais permanecendo constante, no primeiro emprego, um indivíduo entre os $5 \%$ menos qualificados (de menor renda) teria risco instantâneo de demissão num momento qualquer de sua trajetória 16 vezes maior do que alguém entre os 5\% mais qualificados. Este achado pode ser intuitivamente apreendido nos seguintes termos: entre dois indivíduos contratados no mesmo mês, um no topo e outro na base da distribuição de renda, o menos qualificado terá 16 vezes mais chances de ser demitido no mês seguinte do que o mais qualificado. Como conseqüência, ao final de 6 meses, por exemplo, a probabilidade de que os mais mal remunerados tenham perdido o primeiro emprego será de $67 \%$, contra 
apenas 4\% dos "mais ricos". Essas taxas serão de 59\% e 31\% respectivamente no caso do quinto emprego.

No caso do risco de retorno a novo emprego formal, a qualificação tem seu efeito reduzido fortemente a cada novo vínculo, a ponto de ser praticamente anulado no quinto. Lembre-se que a medida utilizada aqui se refere à qualificação acumulada no emprego de demissão. Logo, o que está sendo demonstrado é que, quanto mais o indivíduo rode entre empregos, menos as habilidades práticas por ele ofertadas no mercado de trabalho têm importância na obtenção de um novo posto formal. Ademais, quando a qualificação importa, é na contramão do que seria de se esperar em termos intuitivos: a experiência profissional acumulada joga contra as chances de readmissão, aumentando o tempo de permanência fora do setor formal dos trabalhadores que, no momento da demissão, ocupavam lugares mais elevados na distribuição da qualificação. A experiência pregressa, ou "a vida", representa um passivo no mercado de trabalho ${ }^{9}$.

É claro que os mais qualificados podem não ter procurado trabalho depois da demissão. O tempo de emprego e o salário mais altos, tomados em conjunto, podem significar que o trabalhador se aposentou, ou se fixou por conta própria com o pecúlio que a demissão permite (FGTS, sua multa e outros direitos), ou se encontra, por alguma razão, fora da PEA (invalidez, afazeres domésticos etc.). Não há como afirmar que esses indivíduos estão, todos, estigmatizados pela qualificação. Entretanto, é possível imaginar que esses trabalhadores terão exigências mais intensas com relação ao possível novo posto de trabalho formal. Qualquer nova ocupação que represente perda de status será rechaçada enquanto isso for possível, dadas as necessidades de sobrevivência do trabalhador. Tudo isso pode estar a se refletir no tempo maior despendido fora do setor formal por parte dos mais qualificados, compondo parte importante do referido passivo. O que é interessante reter dos novos dados, porém, é que esse passivo deixa de sê-lo

9 Conclusão semelhante tendo por base a PME-IBGE de 1982 a 1993 pode ser encontrada em Barros, Camargo e Mendonça (1997): a idade, ou a "experiência no mercado de trabalho", reduz as chances de perda de emprego (formal ou informal), mas aumenta o tempo de permanência no desemprego na média do período estudado. 
a cada nova recontratação.

(c) Nesta mesma ordem de achados, as diferenças de idade também perdem poder explicativo dos riscos de demissão ou de retorno quanto maior o número de vínculos. No caso da perda do primeiro emprego, por exemplo, o risco dos adolescentes (até 17 anos) era 4,1 vezes (410\%) maior do que o dos trabalhadores com 50 anos ou mais (população de referência da variável dummy), diferença que caía a 2,83 no segundo e a 1,60 no quinto eventos. Perda equivalente de um vínculo a outro ocorre nas outras faixas de idade até os 29 anos. Note-se, porém, que, internamente a estes 3 primeiros estratos, não há variação relevante: o risco instantâneo de perda de emprego dos adolescentes (até 17 anos) era de algo em torno de 1,5 vezes maior do que os jovens de 18 a 24 anos, que por sua vez era de perto de 2,5 vezes maior do que a daqueles entre 25 e 29 anos independentemente do vínculo ${ }^{10}$. A queda no poder explicativo da idade, pois, ocorre entre os mais jovens (até 29 anos) e os mais velhos (50 anos ou mais), no sentido de que a rotatividade aproxima (mas não anula) o risco de uns e outros perderem seu emprego.

Os trabalhadores mais maduros (30 a 49 anos) correm sempre maior risco de perda de emprego do que os mais velhos, e estas chances são indiferentes quanto ao vínculo do terceiro evento em diante, isto é, são constantes no tempo. Mas a rotatividade aumenta as chances relativas de aqueles trabalhadores perderem o emprego por comparação com os mais jovens quanto mais rodem entre empregos. Isto é, cada novo emprego do trabalhador mais velho é crescentemente mais instável do que o anterior por comparação com os mais jovens.

A renda, ao ser introduzida na análise, muda um pouco o quadro. A partir do segundo emprego, num ponto qualquer da distribuição de renda, e tudo o mais permanecendo constante, as diferenças de idade só são importantes na explicação da sobrevivência no emprego na comparação entre os dois extremos da distribuição, vale dizer, entre os mais jovens (até

10 Para se chegar a estes números, basta dividir cada proporção pelas demais em cada vínculo, nas três faixas de idade. 
29 anos) e os mais velhos (50 anos ou mais). Ter 30, 40 ou 50 anos não faz a menor diferença do segundo vínculo em diante.

Dá-se o mesmo no caso das chances de retorno a um emprego formal (redução cumulativa dos efeitos globais da idade). Se desconsiderarmos os adolescentes, do terceiro vínculo em diante, a única diferença relevante é aquela entre os mais velhos (50 anos e mais) e todas as outras faixas de idade. Note-se que, tanto no modelo sem qualificação quanto no outro, praticamente não há diferença no efeito da idade nas faixas entre 18 e 49 anos: todos migram melhor que os mais velhos, mas a taxas relativamente constantes entre si, ademais globalmente decrescentes. Isto quer dizer, em resumo: que quanto mais jovem o trabalhador, maior a taxa de mortalidade no primeiro e no segundo eventos e maior também o risco de retorno. Para os outros três vínculos, porém, só faz diferença ter 50 anos ou mais: a taxa de mortalidade no emprego destes indivíduos será sempre menor, mas o risco de voltar a um novo emprego, uma vez demitidos, também. Em termos globais, porém, a diferença é cada vez menos importante. Se os indivíduos rodam muito entre empregos e, ao fazê-lo, permanecem por pouco tempo empregados, as razões para isso não devem ser buscadas nas diferenças de idade, com exceção dos mais velhos e dos mais jovens. As demissões, cumulativamente, anulam parte significativa do efeito desta característica central da força de trabalho, que é o tempo de experiência no mercado de trabalho tal como mensurado pela idade, sobretudo para os trabalhadores no auge de sua vida produtiva, isto é, entre 30 e 40 anos.

d) Quando controlamos pela qualificação, a escolaridade formal tem efeito residual sobre o risco de perda de emprego, especialmente do segundo vínculo em diante. Contribui pouco para explicar também porque certos indivíduos permanecem mais tempo do que outros fora do setor formal. Ainda assim, nesse caso específico a direção do efeito era a esperada: quanto maior a escolaridade, menor o tempo de "exclusão" a cada novo vínculo por comparação com os menos escolarizados. Isto indica a 
operação de critérios de seleção (tanto no caso da demissão quanto no da contratação) pelo lado da demanda por trabalho, que tomam em conta a educação formal. Isso ocorre, contudo, numa dimensão muito menos intensa do que seria de se esperar num ambiente de reestruturação produtiva.

Estendamos um pouco o escrutínio da escolaridade, aspecto essencial aqui, por duas razões centrais. Em primeiro lugar, as teorias econômicas sobre desempenho no mercado de trabalho têm na educação um dos (senão o) mais importantes determinantes da renda e do bem-estar social em sociedades de mercado ${ }^{11}$. Barros e Mendonça (1996b), por exemplo, pretendem ter demonstrado que cada ano a mais de escolaridade aumenta em $15 \%$ a renda dos indivíduos no Brasil e que a baixa escolaridade é o principal componente explicativo de nossa desigualdade de renda relativamente aos países latino-americanos e ao resto do mundo. Em segundo lugar, o discurso oficial sobre as causas do desemprego atribui à baixa qualificação da força de trabalho (leia-se, especialmente, escolaridade formal) as mazelas da população que não consegue emprego de qualidade ou mesmo qualquer emprego. Segundo a suposição por trás desse diagnóstico, os novos postos de trabalho no Brasil "real" estariam demarcados por exigências de qualificação comparáveis ao mundo desenvolvido (Barros e Camargo, 1994), já que a reestruturação produtiva estaria produzindo aqui as mesmas conseqüências que lá: os postos de trabalho sobreviventes na indústria estariam a requerer habilidades novas, relacionadas com novas tecnologias digitais e com processos de trabalho mais complexos, baseados em tarefas em equipe, enriquecidas e/ou de ciclo mais largo do que as ocupações típicas da organização parcelar do trabalho, demandando, por isso mesmo, trabalhadores de qualificação elevada; e os setores de apoio à atividade produtiva, também cada vez mais submetidos à competição, estariam dando espaço apenas a trabalhadores de alta produtividade, isto é, mais qualificados e capazes de adaptação a ambientes mutantes de trabalho. 
Ora, o que se discutiu até aqui sugere que a garantia no emprego dos trabalhadores que em algum momento tiveram vínculos em indústrias de material de transportes de São Paulo não é prerrogativa dos mais escolarizados. A qualificação formal que os indivíduos levam consigo ao posto de trabalho é menos importante, em termos agregados, do que aquela que eles adquirem na prática cotidiana de seu labor. Esta corrige o efeito da escolaridade a ponto de inverter seu impacto independente. Em lugar de reduzir o risco de perda de emprego, ser mais escolarizado vem aumentálo a cada novo umbral ${ }^{12}$ no primeiro emprego, até o ponto em que trabaIhadores com nível superior tinham 1/3 mais chances de sair num momento qualquer do que aqueles com primário completo.

É curioso que a qualificação prática corrige a educação no sentido inverso, no caso das chances de retorno a um emprego formal. Elas são maiores a cada novo vínculo a partir do $2^{\mathrm{o}}$ quanto maior a escolaridade formal, ainda que as diferenças não sejam muito grandes, de tal modo que, entre os que rodam mais nos empregos, os indivíduos mais escolarizados, sobretudo aqueles com grau superior, levam menos tempo para retornar ao setor formal do que os outros. É incontestável, porém, que, ao menos até 1995, a escolaridade tinha pouca valia no mercado de trabalho formal por comparação com a qualificação on the job, ou a experiência prática dos indivíduos.

(e) As diferenças de gênero têm forte impacto independente sobre o risco de mudança de estado, sobretudo quando se introduz a renda ou a qualificação nos modelos de demissão ou retorno. Num caso (demissão), os homens tinham chances um pouco menores de perder o emprego apenas no primeiro vínculo, e, nos seguintes, a probabilidade era maior do que para as mulheres, mas a diferença era muito pequena (entre 3,5\% e 7\%) sem a qualificação. Ao introduzir-se essa variável no modelo, ser homem aumentava em $32 \%$ o risco instantâneo relativo de perda de emprego no primeiro evento, diferença que caía a quase $19 \%$ no quinto, ainda assim

12 Por umbral entendo os ciclos completos de escolaridade. O primeiro umbral é o primário, o segundo o ginásio, o terceiro o colegial e o quarto a universidade. 
diferença de monta. Alternativamente, o risco de retorno ao setor formal é mais alto para os homens, mesmo sem o controle da qualificação caindo de $48 \%$ a $29 \%$ do primeiro ao quinto eventos. Com a qualificação no modelo, porém, o gênero do trabalhador importa ainda mais, com os homens apresentando entre $54 \%$ e $31 \%$ mais chances de retorno que as mulheres do primeiro ao quinto vínculos.

O que está sendo demonstrado é que, principalmente quando controlamos pela qualificação, as mulheres levam mais tempo para ser demitidas do que os homens e que, havendo uma demissão, elas também têm maiores dificuldades para conseguir um novo emprego do que eles. Este resultado está em acordo com o que se conhece do funcionamento do mercado de trabalho brasileiro. Barros, Camargo e Mendonça (1997) por exemplo, estudando movimentos de entrada e saída do desemprego na Grande São Paulo na média do período 1982-1993, constatam que as muIheres tinham, em média, probabilidade mensal de $0,75 \%$ de entrada no desemprego, valor que atingia 1,2\% para os homens. Diferença de $60 \%$ em (des)favor deles. Por outra parte, uma vez perdido o emprego, a chance de saída deste estado (volta a novo emprego) era de perto de 13\% para as mulheres, contra mais de $22 \%$ para os homens ( $41 \%$ a mais para eles). Isso fazia com que a duração média do desemprego entre as mulheres fosse de quase 8 semanas, contra pouco mais de 4 semanas entre os homens.

Penso que este é o resultado mais provável num ambiente em que, por hipótese, a desigualdade nas chances de mudança de estado decorre sobretudo de discriminação por gênero no mercado de trabalho. Lembre-se que o que está em causa aqui é a combinação de dois resultados correlatos, que sustento serem duas faces da mesma moeda: mulheres levam mais tempo para perder o emprego, mas ficam mais tempo fora do setor formal do que os homens. É este último indicador que está sugerindo a vigência de maiores barreiras à entrada para elas: no caso dos egressos da indústria de material de transportes paulista analisados aqui, os homens que perdem o primeiro emprego terão mais de $50 \%$ de chances de retornar ao setor for- 
mal no mês seguinte do que as mulheres. E é porque parece haver maiores barreiras à entrada para elas (cujo indicador é o maior tempo de espera fora do formal) que a maior permanência no emprego é mais provável. Vejamos isso mais de perto.

Suponha que uma empresa qualquer incorra nos custos de contratar uma mulher que tenha perdido seu primeiro emprego, contra os filtros sociais que, tudo indica, ainda estigmatizam a força de trabalho feminina. Nesse caso, hipótese plausível parece ser que isto terá decorrido: (I) ou do fato de que a empresa possui ocupações "generificadas", com o que as pressões do mercado de trabalho se restringem fortemente, isto é, não há a competição de homens para a vaga; (II) ou de que, na concorrência com os homens, mulheres de qualificação idêntica "aceitarão" salários menores; (III) ou de que as empresas podem contar com trabalhador mais qualificado do sexo feminino, por um preço inferior ao que pagariam a um homem menos qualificado. Em qualquer desses casos, num ambiente de discriminação, os custos da decisão por uma mulher são superiores aos da decisão por um homem simplesmente porque, embora as qualificações sejam potencialmente idênticas, os indivíduos não são intercambiáveis devido ao sexo. Mas em qualquer das três hipóteses, uma vez tomada a decisão, as pressões do mercado externo de força de trabalho pela substituição das mulheres são menores do que aquelas às quais os homens estão submetidos, dentre outras coisas porque a taxa de desemprego deles é quase sempre superior à delas e porque elas não sofrem a concorrência deles, já que foram contratadas justamente por sua vantagem relativa: o fato de serem mulheres sujeitas à discriminação.

Por outras palavras, se, controlando-se tudo o mais (heterogeneidade da força de trabalho e estrutura do mercado de trabalho), contra as mulheres operam barreiras mais intensas à entrada em um emprego qualquer, e também a um emprego formal por comparação com os homens e, se essas barreiras não podem ser atribuídas a outra coisa senão a distinções associa- 
das de um modo ou de outro às características fisiológicas de cada um, então é possível esperar que a seleção de uma mulher para um posto de trabalho qualquer reflita a delimitação (organizacional ou social) desse posto como "feminino", ou preferencialmente destinado às mulheres, ou que as mulheres têm vantagens comparativas decorrentes de sua posição subordinada em sociedade, o que reduz a concorrência pelos postos de trabalho que venham a ocupar, pelas três razões mencionadas antes. Nesta perspectiva, as diferenças entre homens e mulheres encontradas no mercado de trabalho paulista tornam-se plausíveis com recurso à hipótese de que, apesar da indubitável modernização das relações sociais no país, nas últimas décadas, há resíduo ainda (e ao que parece fortemente) operante de relações "generificadas" de trabalho que, ao mesmo tempo, limitam o acesso das mulheres aos postos de trabalho e reduzem as pressões competitivas sobre aquelas que conseguem um emprego.

(f) Na tentativa de controlar os efeitos da demanda por trabalho e, com isso, isolar o impacto independente das características individuais (oferta) sobre o risco de mudança de estado, introduzi nos modelos indicadores da estrutura do mercado de trabalho, medida pelo setor econômico e pelo tamanho do mercado formal do município de origem. O setor foi incluído na forma de um Índice de Qualidade de Emprego formal, que construí tomando por base o agrupamento das atividades econômicas em 46 setores (que na RAIS têm o nome de "Atividade IBGE"). Construí uma hierarquia segundo a qualidade do emprego em cada um, qualidade definida em função: (I) da proporção de empregados com, pelo menos, primeiro grau completo sobre o total, ou seja, uma medida da qualificação dos postos de trabalho; (II) da renda média em salários mínimos, uma medida da recompensa associada ao posto de trabalho, isto é, de sua raridade relativa; e (III) da taxa de rotatividade setorial, medida enquanto proporção de empregados com até um ano de emprego sobre o total, uma medida das expectativas dos trabalhadores quanto à estabilidade do vínculo empregatício. O índice compõe-se da média aritmética das posições de 
cada setor na distribuição de cada um dos três indicadores e varia de 1 (melhor posição média) a 46 (pior posição média) ${ }^{13}$. Além desse indicador, incluí o tamanho do mercado formal do município de origem como uma variável dummy ${ }^{14}$.

Embora cumpram papel de controle, vale mencionar que o risco de demissão ou retorno não é indiferente ao tamanho do município ou ao setor de atividade. Nos modelos com qualificação, vemos que ter origem em mercados de trabalho médios favorece tanto o reemprego quanto a demissão (portanto, a rotatividade) por comparação tanto com mercados "pequenos" (até 100 mil trabalhadores formais) quanto com os grandes (500 mil ou mais). É verdade que as diferenças não são salientes neste último caso. Mesmo assim, estar empregado em grandes centros urbanos aumenta o tempo de permanência no emprego a cada novo vínculo; por outro lado, reduz as chances de retorno a um emprego formal na primeira demissão, perdendo capacidade explicativa a cada nova demissão, a ponto de anular-se no quinto evento.

Assim também, parece claro que o índice de qualidade de emprego tem efeitos residuais sobre o risco de reemprego, mas não sobre o de demissão. Nesse caso, para cada novo emprego, um ponto a mais na escala de (má) qualidade tem efeitos crescentes (mesmo que pequenos) na redução do tempo de permanência nele. Isto é, quanto mais os indivíduos rodem entre empregos, mais o fato de se empregar em setores de má qualidade reduz o tempo de permanência neles, por comparação com empregados em setores de melhor qualidade de emprego. O efeito médio de $1,74 \%$ por ponto na escala de qualidade, tal como o obtido no quinto emprego, escala que tem 46 posições, se fosse homogêneo a cada ponto implicaria que um indivíduo empregado no pior setor (pesca) teria 2,14

13 Ver Cardoso (2000: cap 4, para detalhes sobre a construção e teste deste índice).

$14 \mathrm{O}$ agrupamento utilizado pode parecer por demais arbitrário. Entretanto, testes estatísticos demonstraram que, acima de 500 mil trabalhadores formais, não há qualquer impacto relevante deste indicador sobre as chances de mudança de estado. Como este corte (500 mil ou mais) englobava pouco mais de 1/3 da força de trabalho formal que teve algum vínculo em empresas paulistas de material de transportes, pareceu prudente agrupar os outros municípios em estratos homogêneos, também com $1 / 3$ da população cada. 
vezes mais chances de perder o emprego no mês seguinte ao da contratação do que alguém no melhor ramo (instituições financeiras).

No caso do risco de reemprego a qualidade do emprego de origem (na demissão) só tem relevância no primeiro vínculo, perdendo inteiramente poder explicativo nos demais. Os trabalhadores que perderam o primeiro emprego retornarão mais rapidamente ao setor formal quanto pior a qualidade dos empregos gerados pelo setor de seu vínculo de origem. Esta constatação é coerente com as chances dos mais qualificados, muito menores a cada vintil no caso da primeira demissão. É de se esperar que setores que geram empregos de pior qualidade "produzam" ou empreguem, também, trabalhadores de menor qualificação. É importante marcar, porém, que isso só se aplica no caso do primeiro vínculo. Nos demais, a qualidade do emprego do setor de origem não contribui em nada para explicar o risco de reemprego e, com ele, o tempo despendido fora do setor formal.

(g) Os modelos são robustos na explicação do risco de demissão, mas o retorno a um novo emprego formal, com exceção do primeiro evento, tem determinantes outros que não os disponíveis na RAIS. Lembro ao leitor que o efeito de uma variável se dá sempre em termos relativos: ser homem aumenta em $32 \%$ o risco de perda de emprego por comparação com as mulheres; a escolaridade superior aumenta em $32 \%$ o risco de demissão por comparação com ter primário completo e assim por diante. Se um modelo perde capacidade explicativa, isto quer dizer que as diferenças entre indivíduos vão deixando de ter relevância na compreensão dos processos em análise, no caso, a taxa de risco de mudança de estado a cada novo vínculo. Isto significa que as causas para um ou outro resultado devem ser buscadas em outro lugar que não a heterogeneidade da força de trabaIho ou a estrutura do mercado de trabalho tal como mensurada aqui. Pode ser, por exemplo, que boa parte da chance de retorno se deva à taxa de 
rotatividade, ou aos ciclos econômicos, ou à reestruturação produtiva, ou ao tamanho do mercado informal nas regiões, aspectos não mensurados diretamente pela RAIS e em relação aos quais ela serve de indicador muito aproximado, talvez mesmo inadequado.

No caso do risco de retorno ao setor formal, isso é perfeitamente evidente. Apenas no primeiro evento, os indicadores disponíveis ajudam a explicar parte relevante da variação nas taxas de reemprego, com $\mathrm{R}^{2}$ de 0,30 no modelo com qualificação, o que significa, grosso modo, que $30 \%$ da variação naquelas taxas podem ser explicados pelas diferenças entre os indivíduos ou na estrutura do mercado de trabalho, medida pelo setor de origem e pelo tamanho do mercado formal de trabalho. Do segundo evento em diante, a proporção da variância da taxa de retorno explicada pelos modelos é muito pequena, inferior a $8 \%$ no segundo evento, e igual a $2 \%$ no último ${ }^{15}$.

A qualificação aumenta sensivelmente a capacidade explicativa global de uma ou outra ocorrência. O risco de demissão no primeiro evento, por exemplo, tem quase $64 \%$ de sua variância explicada pelo modelo com renda, contra $43 \%$ do outro (sem renda). E mesmo com o acúmulo de vínculos pelos indivíduos, o modelo segue com poder explicativo relevante (29\% no quinto evento, por exemplo).

Dizendo de outro modo: as informações disponíveis na RAIS permitem avaliar e explicar de maneira estatisticamente robusta o risco de demissão dos indivíduos, já que esse risco permanece dependente das diferenças entre eles e na estrutura do mercado de trabalho, mesmo entre os que rodam muito entre empregos. Mas o risco de retorno a um novo emprego formal tem determinantes não mensurados pela RAIS, principalmente no caso dos trabalhadores mais instáveis em seus vínculos.

15 Estes valores se repetem se utilizarmos outras medidas de adequação, como a proposta por Aldrich e Nelson (1989), que varia entre 0,27 e 0,02 do primeiro ao quinto emprego; ou a de Veall e Zimmermann (1992), que caem no intervalo 0,26 e 0,02 . 


\section{Conclusão}

Tanto no caso do risco de demissão quanto no de reemprego, pois, as características da força de trabalho demonstram capacidade explicativa bastante saliente das chances relativas dos indivíduos, sobretudo no primeiro de cada um desses eventos. Mas parece evidente que, com poucas exceções, cada novo vínculo tem como principal resultado a redução do efeito relativo de cada variável. A rotatividade funciona como liquidificador das diferenças entre os indivíduos, de tal modo que até mesmo a qualificação perde poder discriminante do risco instantâneo de mudança de estado, sendo praticamente anulada no quinto evento no caso do risco de retorno ao setor formal após uma demissão. Os dados são contundentes em demonstrar que, qualquer que seja a razão para uma demissão, ela pesa na história de vida ocupacional dos trabalhadores como um passivo cumulativo que reduz suas possíveis vantagens comparativas no mercado de trabalho, vantagens tais como a escolaridade mais elevada, a juventude, a maior qualificação etc. Os trabalhadores mais bem equipados para a competição têm menores chances de perda de emprego, mas a taxas decrescentes quanto mais empregos sejam perdidos. Eles retornarão mais rapidamente a um posto formal de trabalho, é verdade, mas apenas a escolaridade continua tendo efeitos relevantes a cada novo vínculo. Tudo o mais se vai diluindo no tempo com a rotatividade.

De qualquer modo, considerando-se apenas o primeiro vínculo da janela observacional analisada aqui (1989-1995), a demissão ocorrerá tanto mais rapidamente: quanto mais jovens os indivíduos; quanto menos qualificados (qualificação medida pela renda); quanto mais escolarizados; quanto maior mercado formal de trabalho na cidade de origem da ocupação; se os indivíduos são homens; e quanto pior o setor de origem em termos da qualidade dos empregos que gera. E a volta a um emprego formal ocorrerá tanto mais rapidamente quanto mais jovens os indivíduos; quanto mais escolarizados; quanto menos qualificados; quanto maioro mercado formal 
de trabalho na cidade de origem da ocupação; se os indivíduos são homens; e quanto pioro setor de origem em termos da qualidade dos empregos que gera.

Ora, o efeito de todos os indicadores, sem exceção, tem a mesma direção num caso e no outro. É verdade que há diferenças na intensidade dos impactos independentes se estamos procurando explicar a demissão ou o retorno. De um modo geral, o efeito é menor no último caso, com exceção do sexo e da idade, sobretudo nos dois primeiros eventos. Mas não deixa de ser surpreendente constatar que as mesmas características dos indivíduos e do mercado de trabalho estão associadas tanto ao tempo de permanência no emprego quanto ao de exclusão do setor formal: o que leva à estabilidade é, também, o que leva à exclusão (especialmente a qualificação). E o que reduz o tempo até a demissão é o que explica o retorno mais rápido (sobretudo o sexo e a idade). Este achado sugere que o mercado de trabalho paulista, tendo em conta a população que, em algum momento, teve vínculos em indústrias de material de transportes, tem parte importante, mas não toda sua dinâmica, determinada pela rotatividade de força de trabalho, por meio da qual as empresas trocam parte de seu contingente por trabalhadores equivalentes, disponíveis no mercado de trabalho. É interessante salientar que a escolaridade reduz o tempo de espera fora do setor formal a cada nova demissão, ao passo que vai perdendo impacto sobre o tempo de permanência no emprego a cada novo vínculo. Isto é o mesmo que dizer que as empresas, em suas políticas de rotatividade, dão preferência a trabalhadores com maior qualificação formal na contratação, mas na demissão isto é, em parte e crescentemente, indiferente.

A rotatividade se marca na vida empregatícia de cada um de forma indelével, mas de uma maneira curiosa: ela aumenta o tempo global de permanência do indivíduo no mercado formal, enquanto os que ficam muito tempo no mesmo emprego dificilmente retornam após uma demissão. Isto significa que o trabalhador "mais empregável" é aquele que mais roda entre empregos, se definirmos "empregabilidade" como habilidade de acesso 
a um emprego formal qualquer. Porém, o paradoxo está em que as maiores chances de reemprego encontram-se nos setores que geram as piores ocupações (mais mal remuneradas, de baixa escolaridade e alta rotatividade). Um emprego nas indústrias de material de transportes, pois, parece estar estigmatizando seus trabalhadores mais qualificados quando estes são demitidos, ao passo que a rotatividade dilui quase toda a diferença entre os indivíduos, com exceção daquela associada ao gênero.

O gênero, aliás e como esperado, mostrou-se ponto de clivagem em si mesmo, independente de tudo o mais. Em qualquer situação, sob quaisquer pretextos, com emprego em alta ou em baixa, entre os mais e os menos escolarizados, mais mal, ou mais bem remunerados, em posições operárias ou administrativas, no topo ou na base da escala de qualificação e renda, as mulheres levarão mais tempo para ser demitidas do que os homens, e terão maiores dificuldades de retorno a um posto formal do que eles. As diferenças giram em torno de 1/3.

Finalmente, é sem dúvida importante a demonstração de que a escolaridade formal tem efeito inteiramente residual nas chances de perda de emprego e muito pequena nas de retorno ao mercado formal, quando controlamos pela qualificação on the job, especialmente do segundo vínculo em diante em que, quase sempre, a ocupação ocorre em uma empresa fora do segmento de material de transportes e, ademais, fora da indústria. Os critérios de seleção para a demissão parecem dar maior ênfase ao investimento das empresas em capital humano, expresso no tempo de emprego, do que dos trabalhadores, expresso na escolaridade formal. Nessas condições, a maior garantia de que o trabalhador não será demitido é a permanência no emprego. Embora aparentemente tautológica, o que esta afirmação denota é que $o$ risco de perda do emprego, num momento qualquer do tempo, é fortemente dependente de fatores do lado da demanda por trabalho: a disposição dos empregadores em investir em capital humano mostrou-se largamente mais importante do que a dos trabalhadores em investir em escolarização, e o fator decisivo para a manutenção do empre- 
go parecem ser as políticas de gestão da força de trabalho, não tanto os ativos que os trabalhadores ofertam no mercado.

\section{Referências bibliográficas}

ALDRICH, J.H.; NELSON, F. D. Linear probability, logit, and probit models. Beverly Hills, Sage, 1989.

ALLISON, Paul D. Event history analysis. Regression for longitudinal event data. Newbury Park and Sage, Sage University Paper (46), 1984.

ALLMENDIGER, Jutta. Career mobility dynamics: a comparative analysis of the United States, Norway, and West Germany. Berlin, Max-Planck-Institu für Bildungsforschung, 1989.

AURIAT, Nadia. My wife knows best: a comparison of event dating accuracy between the wife, the husband, the couple and the Belgium population register. Public Opinion Quarterly, Chicago, v.57, p.165-190, 1993.

BAKER, Meredith e ELIAS, Peter. Youth unemployment and work histories. In: DEX, Shirley (Ed.). Life and work history analyses. London, Routledge, 1991. p.214244.

BARBARY, Olivier. Analysis tipologico de datos biográficos en Bogota. Bogota, Universidad Nacional de Colombia, Dep. de Mat. e Estatística, 1996.

BARROS, Ricardo P. de; CAMARGO, José Márcio. Porca miséria II: as causas da pobreza no Brasil. Texto para discussão, Rio de Janeiro, n.320, 1994.

BARROS, Ricardo P. de Barros; MENDONÇA, Rosane. Salários e educação no Brasil. Rio de Janeiro, IPEA, 1996b.

BARROS, Ricardo P. de; CAMARGO, José Marcio; MENDONÇA, Rosane. Determinantes da pobreza no Brasil. Rio de janeiro, IPEA, 1996. (Série Seminários 19(96)).

BARROS, Ricardo P. de; CAMARGO, José Márcio; MENDONÇA, Rosane. A estrutura do desemprego no Brasil. Textos para discussão, Rio de Janeiro, n:478, 1997.

BLOSSFELD, Hans-Peter. Entry into the labor market and occupational career in 
the Federal Republic: a comparison with american studies. International Journal of Sociology, v.17, n.1-2, p.86-115, 1987a.

BLOSSFELD, Hans-Peter. Labor market entry and the sexual segregation or careers in the Federal Republic of Germany. American Journal of Sociology, Chicago, v.93, n.1, p.89-118, 1987b.

BLOSSFELD, Hans-Peter; ROHWER Götz. Techniques of event history modeling: New approaches to causal analysis. New Jersey, Erlbaum. 1995.

BLOSSFELD Hans-Peter; HAMERLE, Peter; MAYER, Karl Ülrich. Event history analysis: Statistical theory and application in the social sciences. New Jersey and London, Erlbaum, 1989.

CARDOSO, Adalberto M. Globalização e relações industriais na indústria automobilística brasileira: um estudo de caso. Avances de Investigación, Puebla, n.2, 1995.

CARDOSO, Adalberto M. O trabalho em trânsito: trajetórias profissionais dos deserdados da indústria. Rio de janeiro, FGV (no prelo), 2000.

CASTRO, Nadya A.; CARDOSO, Adalberto M.; CARUSO, Luis A. Trajetórias ocupacionais, desemprego e empregabilidade. Há algo de novo na agenda dos estudos sociais do trabalho o Brasil? Contemporaneidade e Educação, Rio de Janeiro, v.2, n.1, p.7-23, 1997.

CEPAL/UNESCO. Educación y conocimiento: eje de la transformación productiva con equidad. Santiago de Chile, Cepal, 1992.

COURGEAU Daniel. Métodos para el análisis de datos biográficos. In BARBARY, Olivier (Ed.). Annales del seminário internacional: recolección y análisis de datos longitudinales. Bogotá, Universidad Nacional de Colombia, 9-13 de dec. 1996, 1996b. p.303-329.

ELIAS, Peter. Occupational Change in a working-life perspective: Internal and external views. In: PENN, Roger; ROSE, Machael; RUBERRY, Jill (Eds.). Skill and occupational change. Oxford, Oxford University Press, 1994. p.75-106.

ESTRELLA, Arturo. A new measure of fit for equations with dichotomous dependent variables. Journal of Business and Economic Statistics, v.16, n.2, p.198-205, 1998.

FEATHERMAN, David L. Biography, society, and history: individual development as a population process. In: SORENSEN, Aage; WEINERT, Franz; SHERROD, Lonnie. Human development and the life course: multidisciplinary perspectives. London/ 
Hillsdale, Lawrence Erlbaum, 1986. p.99-149.

FEATHERMAN David L.; SALBEE, Kevin L.; MAYER, Karl U. Social classe and the structuring of life course in Norway and West Germany. In: KERTZER, David; SCHAIE, Wagner K. Age structuring in comparative perspective. Hillsdale, Lawrence Erlbaum, 1989.

GITAHY, Leda; BRESCIANI, Luis P. Reestruturação produtiva e trabalho na indústria automobilística. Textos para Discussão, Campinas, n.24, 1998.

HUMPHREY, John. The manegement of labour and the move towards leaner production systems in the third world: the case of Brazil. Texto apresentado no seminário internacional The Challenge of Lean Production: How are Firms and Unions Responding, Genebra, 5-6 de novembro, 1992. 29p.

LAVINAS, Lena. Emprego feminino: o que ha de novo e o que se repete. Dados, Rio de Janeiro, v.40, n.1, p.41-67, 1997.

MAYER, Karl Ülrich; HUININK, Johannes. Age, period ans cohort in the study of life course: a comparison of classical A-P-C-analysis with event history analysis, or Farewell to Lexis? In: MAGNUSSON, David; BERGMAN, Lars R. (Eds.). Data quality in longitudinal research. Cambridge, Cambridge University Press, 1990. p.211232.

MAYER, Karl Ülrich; TUMA, Nancy B. Life course research and event history analysis: an overview. In: MAYER, Karl U.; TUMA, Nancy B. (Eds.). Event history analysis in life course research. Madison, The University of Wisconsin Press, 1990. p.3-20. MAYER, Karl Ülrich; CARROLL, Glenn R. Jobs and classes: estructural constraints on career mobility. European Sociological Review, Oxford, v.3, n.1, p.14-38, 1987.

PRYOR, F. L.; SCHAFFER, D. L. Who is not working and why. Cambridge, Cambridge University Press, 1999.

TODD, Emmanuel Todd. L'enfance du monde. Structures familiales et développement. Paris, Le Seuil, 1984.

VEALL, M. R.; ZIMMERMANN, K. F. Pseudo $\mathrm{R}^{2 \prime}$ s in the Ordinal Probit Model. Journal of Mathematical Sociology, n.16, p. 333-342, 1992.

WALBY Sylvia. Labour markets and industrial structures in women's working lives. In: DEX, Shirley (Ed.). Life and work history analyses. London, Routledge, 1991. p.167-186. 


\section{Resumo}

O estudo visa sanar uma lacuna existente na literatura sobre reestruturação produtiva no Brasil, tradicionalmente voltada para a análise da organização do trabalho e dos empregos que sobrevivem às mudanças. Sabe-se muito pouco sobre as opções de trabalho daquelas pessoas que são direta e negativamente afetadas pela reestruturação. Logo, em lugar de argüir a tecnologia para então buscar na estrutura social o trabalhador mais adequado aos novos postos de trabalho, cumpre argüir a estrutura mesma de oferta e demanda de força de trabalho para desvelar as potencialidades efetivas de incorporação produtiva e social dos trabalhadores que tiveram no mundo fabril seu projeto de emprego, mas que vêem suas opções ocupacionais restringidas pela destruição estrutural de postos de trabalho. Como hipótese global de trabalho, parece plausível suspeitar que, quanto mais sistêmica a reestruturação de um setor qualquer, maiores os riscos de perda do emprego e menores as chances de reinserção profissional dos demitidos, de tal modo que se preservem o capital qualificacional e a qualidade de emprego de origem. Esta hipótese é investigada por meio de análise de história de eventos, tendo como objeto os empregados nas indústrias de material de transportes do Estado de São Paulo nos anos 1990.

Palavras-chave: Mercado de trabalho, indústria automobilística, trajetórias ocupacionais, Brasil. 